\title{
Are bacterial counts on slit-skin smears in leprosy affected by preparing slides under field conditions?
}

\author{
JOANNA SAYER*, R GENT $\dagger \&$ K JESUDASAN $\ddagger$ \\ *Hereford County Hospital, Hereford HRI 2ER; †John Radcliffe \\ Hospital, Oxford OX3 9DU; $\ddagger$ Schieffelin Leprosy Research and \\ Training Centre, Karigiri, North Arcot District, Tamil Nadu, India
}

\begin{abstract}
Accepted for publication 10 March 1987
Summary A study was undertaken to look at two of the factors which may have an effect on the Bacteriological Index (BI) of slit-skin smears collected in the field. The effect of sunlight during air-drying of the smears was examined by comparing smears dried in sunlight with those dried in darkness or in the shade. The results showed no significant difference in the $\mathrm{BI}$ readings of the slides from the three different groups.

A second set of slit-skin smears were used to investigate whether staining would be affected by delaying the staining of the fixed smears by intervals of one week and three weeks. The readings from these various groups also showed no significant difference. However, there was a trend towards lower readings in the slides that had been stored for longer periods.
\end{abstract}

The relevance of these findings for leprosy field workers is discussed.

\section{Introduction}

Accurate slit-skin smear examination in leprosy is important for the classification and occasionally the diagnosis of leprosy. Classification of leprosy patients has important implications for their medical management.

The World Health Organisation stresses the importance of uniformity and reliability of technique when preparing slit-skin smears in order to assign patients to multibacillary or paucibacillary groups for multidrug treatment regimes. ${ }^{1}$

Technical manuals for smear collection and staining ${ }^{2}$ advise that the smears should be dried in shaded conditions. Exposure of the smears to bright sunlight, either during preparation and staining or subsequently during storage as reference slides, may affect the staining properties of the bacilli so that they no longer take up the stain or, if already stained, they fade. This may cause difficulties when estimating the Bacteriological Index (BI) of the smear so that the patient's bacillary load may be underestimated. 
Under field conditions, slit-skin smears may become exposed to bright sunlight during their preparation or during transport back to the base hospital for staining. Our experience in village clinics in South India has shown that although the smear may be placed in the shade to dry, it may become exposed to sunlight as the shadows move.

Another factor which may affect the ability of the bacilli to take up stain is the length of the delay between preparation of the smear and its arrival in the laboratory for staining. Either the delay itself, or intermittent exposure to light as the slide storage box is opened and closed, may affect the staining. In large control areas where the control teams have to travel over difficult terrain, there may be a delay of some days or even weeks between the collection of the smears and their arrival at the base hospital for staining.

This study was undertaken to investigate the importance of technique in the preparation of slit-skin smears in the field. The first part of the study looked at the effect of drying the slides in sunlight for short periods prior to fixation. The second part of the study investigated whether an interval of one or three weeks between fixation and staining would affect the number of bacilli seen when the smears were then stained and examined.

\section{Patients and methods}

\section{EFFECT OF DRYING SLIT-SKIN SMEARS IN DIRECT SUNLIGHT}

Patients for this study were selected from those attending monthly clinics as part of a leprosy control programme in Tamil Nadu, South India. Sites for smears were selected on the basis of a previous positive $\mathrm{BI}$ of $2+$ or greater, taken within the past 12 months. This value was chosen because the changes that could be expected on a smear with less than 10 bacilli per hundred high power fields (BI of $1+$ ) were unlikely to be detected on routine examination.

Twenty smears were taken from 15 patients attending roadside clinics. Two sites were used on five patients. A further 9 smears were taken from patients attending a clinic at one of the base hospitals. Two sites were used on one patient and three sites on two patients. Patients' ages ranged from 10 to 61 years (mean $35 \cdot 1$ years). There were 12 males and 7 females. All the patients had lepromatous or borderline lepromatous leprosy and were receiving treatment either with dapsone alone or following the WHO guidelines for multidrug treatment regimes.

Three smears were taken from each site onto three separate microscope slides. Ridley and Ridley have shown that duplicate smears can be taken from the same site without affecting the BI, provided that the site has a high bacillary load. ${ }^{3}$ The method used followed that described by Leiker and McDougall, ${ }^{2}$ based on an original reference from Wade, ${ }^{4}$ One smear was immediately placed in a lightproof box to dry. This was used as a control. One smear was left in incidental 
sunlight to dry and the third smear was placed in the shade. Care was taken to avoid the smears in sunlight being shaded or those in the shade being exposed to the sun during the drying time.

The smears were left for 5-10 min to dry. All smears from the same site were dried for the same length of time. The allocation of the first, second and third smears to either sunlight, shade or darkness was varied randomly for each patient.

Table 1. Patient data and bacteriological index of smears from the first study comparing smears dried in darkness with equivalent smears dried in sunlight or in the shade.

\begin{tabular}{|c|c|c|c|c|c|c|}
\hline \multirow[b]{2}{*}{ Patient } & \multirow[b]{2}{*}{ Age } & \multirow{2}{*}{ Sex } & \multirow{2}{*}{$\begin{array}{l}\text { Site of } \\
\text { smear }\end{array}$} & \multicolumn{3}{|c|}{ Bacteriological Index } \\
\hline & & & & Darkness & Sunlight & Shade \\
\hline 1 & 38 & $\mathrm{~F}$ & thigh & $2+$ & $2+$ & $2+$ \\
\hline 2 & 40 & $\mathbf{M}$ & earlobe & $4+$ & $3+$ & $4+$ \\
\hline 3 & 26 & $\mathrm{~F}$ & earlobe & $3+$ & $3+$ & $3+$ \\
\hline 4 & 23 & $\mathrm{~F}$ & forehead & $2+$ & $2+$ & $2+$ \\
\hline 5 & 36 & $\mathbf{M}$ & buttock & $3+$ & $3+$ & $3+$ \\
\hline 6 & 10 & $\mathbf{M}$ & buttock & $2+$ & $2+$ & $2+$ \\
\hline 7 & 61 & $\mathbf{M}$ & earlobe & $1+$ & $1+$ & $1+$ \\
\hline \multirow[t]{2}{*}{8} & 46 & $\mathbf{M}$ & forehead & $4+$ & $4+$ & $4+$ \\
\hline & & & buttock & $1+$ & $1+$ & $1+$ \\
\hline \multirow[t]{3}{*}{9} & 42 & $\mathrm{~F}$ & earlobe & $1+$ & $1+$ & $1+$ \\
\hline & & & forehead & $2+$ & $1+$ & $2+$ \\
\hline & & & chin & $1+$ & $2+$ & $1+$ \\
\hline \multirow[t]{3}{*}{10} & 20 & $\mathrm{~F}$ & earlobe & $3+$ & $2+$ & $3+$ \\
\hline & & & forehead & $2+$ & $2+$ & $2+$ \\
\hline & & & chin & $3+$ & $2+$ & $2+$ \\
\hline 11 & 50 & $\mathbf{M}$ & buttock & $2+$ & $2+$ & $3+$ \\
\hline 12 & 24 & $\mathbf{M}$ & earlobe & $2+$ & $2+$ & $2+$ \\
\hline \multirow[t]{2}{*}{13} & 25 & $\mathrm{~F}$ & earlobe & $1+$ & $1+$ & $1+$ \\
\hline & & & chin & $3+$ & $3+$ & $3+$ \\
\hline \multirow[t]{2}{*}{14} & 51 & $\mathbf{M}$ & earlobe & $1+$ & $1+$ & $1+$ \\
\hline & & & chin & $1+$ & $1+$ & $1+$ \\
\hline 15 & 46 & $\mathbf{M}$ & earlobe & $2+$ & $3+$ & $2+$ \\
\hline \multirow[t]{2}{*}{16} & 46 & $\mathbf{M}$ & earlobe & $2+$ & $3+$ & $1+$ \\
\hline & & & chin & $1+$ & $1+$ & $1+$ \\
\hline \multirow[t]{2}{*}{17} & 26 & $\mathrm{~F}$ & earlobe & $1+$ & $1+$ & $1+$ \\
\hline & & & chin & $1+$ & $1+$ & $1+$ \\
\hline 18 & $?$ & $\mathbf{M}$ & earlobe & $2+$ & $3+$ & $2+$ \\
\hline \multirow[t]{2}{*}{19} & 22 & $\mathbf{M}$ & earlobe & $3+$ & $3+$ & $3+$ \\
\hline & & & forehead & $3+$ & $3+$ & $3+$ \\
\hline
\end{tabular}


After drying the smears, the slides were heat-fixed by passing them over the flame of a spirit lamp. They were then stored in a conventional slide box.

All the smears were transported back to the base hospital at the end of the clinic. The following day they were stained with a Ziehl-Neelsen stain using the technique described by Thangaraj..$^{5}$ This is the technique routinely used at this hospital. The smears were examined blind by a laboratory technician who regularly examines slit-skin smears. The BI was recorded according to the Ridley BI. $^{6}$

The lightproof box was constructed from a cardboard slide box. The inside of the box was painted matt black and the lid of the box was raised on two cardboard supports to allow air to circulate through the box, but not sufficiently high to allow light to enter the box.

\section{EFFECT OF DELAYED STAINING ON THE READING OF SLIT-SKIN SMEARS}

Patients were selected from medical outpatients and inpatients at a leprosy hospital in South India. All the patients had had a previous smear with a BI of $2+$ or above, which had been taken within the previous year. Thirty smears were taken from 26 patients. The patients' ages ranged from 17 to 55 years (mean 37 years) and there were 20 males and 6 females. The patients were suffering from lepromatous, borderline lepromatous or borderline leprosy and they were all receiving treatment. Four smears were taken from each site, using the technique described by Leiker and McDougall. ${ }^{2}$ The smears were dried in the shade for 5 min and then heat fixed.
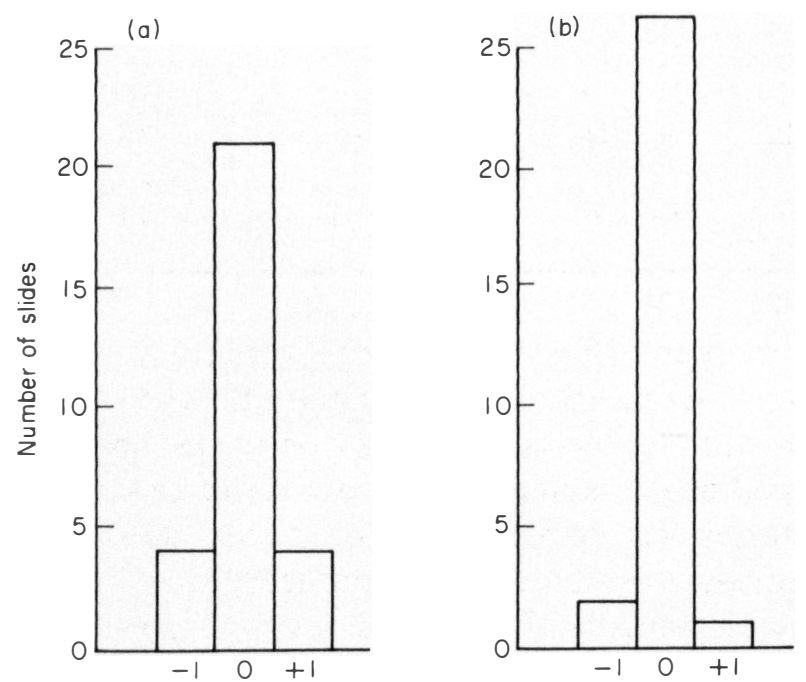

Change in $\mathrm{BI}$

Figure 1. The change in $\mathrm{BI}$ of corresponding slit-skin smears dried in sunlight (a) and dried in shade (b), compared with identical smears dried in darkness. An increase in the BI is indicated by a positive change. 
Table 2. Patient data and bacteriological index of smears for the second study comparing smears that were stained and read on the day following their preparation with equivalent smears that were stained and read after an interval of one week or three weeks.

\begin{tabular}{|c|c|c|c|c|c|c|}
\hline \multirow[b]{2}{*}{ Patient } & \multirow[b]{2}{*}{ Age } & \multirow[b]{2}{*}{ Sex } & \multirow{2}{*}{$\begin{array}{l}\text { Site of } \\
\text { smear }\end{array}$} & \multicolumn{3}{|c|}{ Bacteriological Index } \\
\hline & & & & 2 days & $8-9$ days & $22-23$ days \\
\hline 1 & 26 & $\mathrm{~F}$ & earlobe & $4+$ & $4+$ & $3+$ \\
\hline 2 & 36 & $\mathbf{M}$ & earlobe & $5+$ & $5+$ & $5+$ \\
\hline 3 & 49 & $\mathbf{M}$ & earlobe & $2+$ & $3+$ & $3+$ \\
\hline 4 & 33 & $\mathbf{M}$ & earlobe & $3+$ & $3+$ & $3+$ \\
\hline 5 & 17 & $\mathrm{~F}$ & forehead & $3+$ & $3+$ & $3+$ \\
\hline 6 & 47 & $\mathbf{M}$ & forehead & $4+$ & $4+$ & $4+$ \\
\hline 7 & 31 & $\mathbf{M}$ & forehead & $4+$ & $4+$ & $4+$ \\
\hline 8 & 46 & $\mathbf{M}$ & forehead & $5+$ & $4+$ & $4+$ \\
\hline \multirow[t]{2}{*}{9} & 36 & $\mathbf{M}$ & earlobe & $4+$ & $3+$ & $3+$ \\
\hline & & & forehead & $2+$ & $3+$ & $2+$ \\
\hline 10 & 45 & $\mathbf{M}$ & earlobe & $4+$ & $1+$ & $2+$ \\
\hline 11 & 35 & M & forehead & $2+$ & $2+$ & $1+$ \\
\hline 12 & 34 & $\mathrm{~F}$ & earlobe & $3+$ & $3+$ & $4+$ \\
\hline \multirow[t]{2}{*}{13} & 44 & $\mathbf{M}$ & earlobe & $4+$ & $4+$ & $4+$ \\
\hline & & & forehead & $3+$ & $3+$ & $3+$ \\
\hline 14 & 19 & $\mathbf{M}$ & buttock & $2+$ & $2+$ & $1+$ \\
\hline 15 & 37 & $\mathrm{~F}$ & forehead & $3+$ & $3+$ & $2+$ \\
\hline \multirow[t]{2}{*}{16} & 35 & $\mathbf{M}$ & earlobe & $4+$ & $4+$ & $5+$ \\
\hline & & & forehead & $5+$ & $4+$ & $5+$ \\
\hline 17 & 31 & $\mathbf{M}$ & earlobe & $3+$ & $1+$ & $2+$ \\
\hline 18 & 31 & $\mathbf{M}$ & earlobe & $3+$ & $3+$ & $3+$ \\
\hline \multirow[t]{2}{*}{19} & 24 & $\mathbf{M}$ & earlobe & $4+$ & $4+$ & $3+$ \\
\hline & & & forehead & $3+$ & $3+$ & $2+$ \\
\hline 20 & 36 & $\mathbf{M}$ & forehead & $2+$ & $2+$ & $2+$ \\
\hline
\end{tabular}

The smears were then allocated to one of three groups, the fourth slide being kept as a spare. The first smear was stained and examined within 48 hours using the Ziehl-Neelsen staining technique employed in the hospital. ${ }^{5}$ Those smears with a $\mathrm{BI}$ of $1+$ and negative smears were excluded from the study at this stage. The remaining smears were stored in a closed wooden slide storage box. The second group of smears was stained and examined 8-9 days after they were taken. The third group was stained and examined at 22-23 days.

\section{Results}

Table 1 shows patient data and the results obtained from smears dried in 

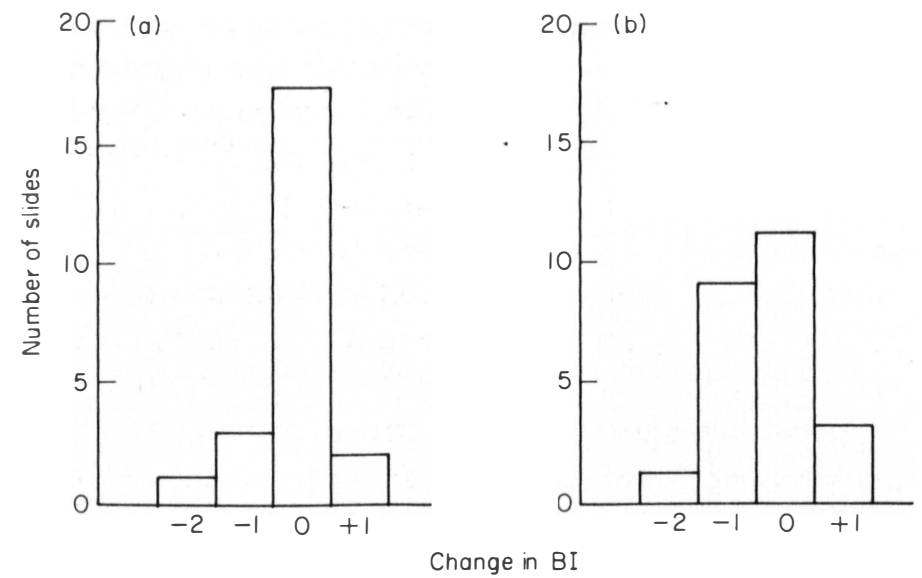

Figure 2. The change in BI after one week (a) and after three weeks (b), compared with the control smears stained and read immediately after they had been taken. An increase in the BI is indicated by a positive change.

darkness, shade and direct sunlight. The BI of smears dried in the lightproof box was used as a control for comparison with smears dried in the shade or in sunlight. This is illustrated in Figure 1 which was constructed by calculating changes in the $\mathrm{BI}$ between the control smear and the corresponding smear dried in sunlight or shade. An increase in the BI is indicated by a positive change. Analysis of the variance using the method described by Bailey ${ }^{7}$ showed no significant change between the slides dried in sunlight, shade or in darkness at $95 \%$ confidence limits.

Table 2 shows data relating to the second study looking at the effect of a delay in staining and reading slit-skin smears. The effect of the delay in staining on the $\mathrm{BI}$ is illustrated in Figure 2. The slides stained and read within $48 \mathrm{~h}$ were used as the control. A positive change indicates an increase in BI. The differences between the groups is not statistically significant.

\section{Discussion}

Although our results show no significant difference between the values for BI recorded on the day after the smears were collected and the values recorded at one week and at three weeks, they appear to show a trend of decreasing values with increasing delay before staining. This trend may disappear if the experiment is repeated with a larger number of samples. It would be informative to repeat this work with a larger number of subjects and look at the effect of a longer delay between fixation and staining.

The results from our studies suggest that exposure to sunlight for short periods during the drying of the smear under field conditions will not significantly affect the BI. 
This work corresponds with that of Dharmendra \& Mukerjee ${ }^{8,9}$ who found no change in the staining properties of leprosy bacilli after short periods of exposure to sunlight of up to $30 \mathrm{~min}$. However longer exposures (greater than $6 \mathrm{~h}$ ) did decrease the proportion of bacilli that were stained. This work was done using bacilli from a nodule on the ear of a lepromatous patient. It is not clear whether the smears were exposed to light before or after fixation.

They extended their investigations to look at the elements of the spectrum that were involved. Since the smears were protected by wrapping them in black paper they concluded that the shorter ultraviolet (UV) wavelengths were the ones that were producing these changes. They confirmed this using an ultraviolet lamp. Mukerjee ${ }^{10}$ later showed that similar changes in staining could be produced by Xirradiation. Corcos ${ }^{11}$ was able to protect the leprosy bacilli from these changes in their staining properties by first boiling the bacilli for $30 \mathrm{~min}$.

Most of the studies mentioned above used prolonged periods of exposure to sunlight, UV-irradiation or X-irradiation to alter the staining properties of the bacteria. Our work has looked at the effect of relatively short exposures under usual field conditions. We have found no significant effect on the BI of slides as a result of these short periods of exposure and therefore do not suggest that any further precautions need to be taken during collection and fixing of slit-skin smears in the field. However, it is important to ensure that the fixed smears are placed in a lightproof slide box for transportation back to the base hospital and that they remain protected from light, especially of short wavelength until after they have been stained and read.

The results from our study do not allow us to draw any definite conclusions about the effect of storage on fixed, unstained smears. It is possible that storage may alter the bacterial staining properties to produce a falsely low BI. We would recommend that field workers should stain and read their slit-skin smears as soon as possible after collecting them.

\section{Acknowledgments}

We wish to acknowledge the help we received from Dr E P Fritschi and the staff at Schieffelin Leprosy Research and Training Centre; Karigiri, North Arcot District, Tamil Nadu, South India during this study. We should like to thank Dr Arunthati for allowing us to take smears from her patients. We should also like to thank the laboratory technicians at Karigiri and Gudiyatham Hospitals for their help with staining and reading the smears.

\section{References}

1 WHO Study Group. Chemotherapy of leprosy for control programmes. Technical Report Series No. 675. WHO: Geneva, 1982. 
2 Leiker DL, McDougall AC. Technical guide for smear examination for leprosy by direct microscopy. Amsterdam: Leprosy Documentation Service (INFOLEP), 1983.

3 Ridley MJ, Ridley DS. Stain techniques and the morphology of Mycobacterium leprae. Lepr Rev, 1971; 42: 88.

4 Wade HW. The bacteriological examination in leprosy. Lepr Rev, 1935; 6: 54-60.

5 Thangaraj RH. A manual of leprosy. New Denli: Printaid, 1975.

6 Ridley DS. Bacterial Indices. In Cochrane RG, Davey TF (eds), Leprosy in theory and practice, 2nd ed. Bristol: John Wright, 1964: 620.

7 Bailey NTJ. Statistical methods in biology, 2nd ed. London: Hodder and Stoughton, 1981.

${ }^{8}$ Dharmeudra, Muker jee N. Memoria del V Congreso Internacional de la lepra. La Habana, Cuba, 1948.

9 Dharmendra, Mukerjee N. Effect of sunlight on the staining properties of the leprosy bacillus. Lep Rev, 1949; 20: 111-4.

${ }_{10}$ Mukerjee N. Differentiation of the human and rat leprosy bacilli by irradiation. Lepr Ind, 1951; 23(4): 196-200.

1 Corcos MG. Human lepra bacilli exposed to sunlight will retain their acid fastness if they are first heated. Lepr Rev, 1953; 24: 165.

\section{NEWS AND NOTES}

\section{AMREF, East Africa}

AMREF works for better health for people in East Africa; mainly in Kenya, Somalia, Southern Sudan, Tanzania and Uganda.

For the last 30 years, AM REF has created and organised health care projects that are relevant and useful in the rural communities. Our Flying Doctor Service takes health care to isolated regions; our immunization programmes protect the young against preventable diseases: our training of Community Health Workers means practical health care is a part of everyday life; and our medical research work saves lives and develops techniques of fighting ill-health that are cheap and appropriate in a rural situation.

We are a charity. We make no profits and depend on funds from government and non-government aid agencies in Africa, Europe and North America, as well as from private donors. AMREF has eight international offices in Canada, Denmark, France, Germany, the Netherlands, North America, Sweden and the United Kingdom and our headquarters are in Nairobi, Kenya.

For further information please contact: African Medical and Research Foundation, London House, 68 Upper Richmond Road, London SW15 2RP.

Tel: 01-874 0098 .

\section{LEPRA Prize Essay Competitions, Medical Schools, UK}

The prize-winning article for 1985, by Mr Michael Maier, a medical student from London, was on the subject of 'The relationship between allergy and immunity in leprosy' and it has been published in the International Journal of Leprosy, Volume 55, Number I, March 1987. We are most grateful to the Editor, Dr R C Hastings, for his continued interest in the prize-winning entries, through the years. For 1986, Paul Klenerman of Oxford ('Aetiological Factors in Delayed Type Hypersensitivity Reactions in Leprosy') and Karim Meeran of London ('Treatment Failure in Leprosy and Tuberculosis') shared an equal first prize. For 1987, the alternatives are: 'Mycobacterial Infections in the Immunocompromised Host; Present and Future Prospects' or 'The Need for New Drugs in the Treatment and Control of Leprosy'. The closing date is the end of 1987. Further enquiries to Dr C Kelly, LEPRA, Fairfax House, Causton Road, Colchester, COI I PU, England.

[These essay competitions for UK medical students have been run every year for nearly 18 years. There are never a large number of entries, but, almost invariably there is at least one of outstanding quality. The total available prize money has now risen to $£ 500$ for each year. Although the cost-effectiveness of this exercise is difficult to assess, LEPRA has the impression that the money is well spent and there is certainly evidence that entry has in many cases led to the student going abroad to work in leprosy during an elective period or to participation in leprosy research, after qualification. Editor.] 